\title{
DESIGN OF COMPLIANT MECHANISMS FOR NEW AGE INDUSTRY DEVICES -
}

\section{A TOPOLOGY OPTIMISATION APPROACH}

\author{
G. ARUNKUMAR ${ }^{1}$, S. LAKSHMI SANKAR ${ }^{2} \&$ S. PADMAGIRISAN ${ }^{3}$ \\ ${ }^{I}$ Professor and Head, Department of Mechanical Engineering, Sathyabama University, Chennai, Tamil Nadu, India \\ ${ }^{2}$ Associate Professor, Department of Mechanical Engineering, Sathyabama University, Chennai, Tamil Nadu, India \\ ${ }^{3}$ Adjunct Faculty, Department of Mechanical Engineering, EMBRY-RIDDLE Aeronautical University, Arizona, United States
}

\section{ABSTRACT}

Compliant Mechanism also transfers or transforms motion, force or energy. Unlike rigid-link mechanisms, however, compliant mechanisms gain at least some of their mobility from the deflection of flexible members rather than from movable joints only. An advantage of compliant mechanisms is the potential for a dramatic reduction in total number of parts required to accomplish a specified task. Some mechanisms may be manufactured from an injection moldable material and be constructed of one piece. Fewer parts are required for the compliant mechanisms than for the rigid mechanisms to accomplish a specified task. Compliant mechanism also has fewer movable joints, such as pin and sliding joints. This results in reduced wear and need for lubrication. Reducing the number of joints can also increase mechanism precision, because backlash may be reduced or eliminated. This has been a factor in the design of high precision new age devices. Authors proposed a topology Optimization method for designing a new age compliant amplifier. Three types of configurations (Rectangular, taper, hexogonal domain) with surface constraints (left and right end of the surface are fixed) have been taken for analysis. The design of new age device compliant amplifier derived from Rectangular, Taper and Hexogonal domain using topology Optimizations and the same is used for amplifying the displacement for opening and closing of a Proportional values and vibrating the micro chute.

KEYWORDS: Compliant Mechanisms, Geometric Advantage, Topology Optimisation \& Numerical Experiments

Received: Nov 02, 2017; Accepted: Nov 15, 2017; Published: Dec 14, 2017; Paper Id.: IJMPERDDEC201773

\section{INTRODUCTION TO COMPLIANT MECHANISM}

Mechanism is a mechanical device used to transfer the force, motion or energy from input to output. But compliant mechanism is a flexible structure that elastically deforms without joints to produce a desired force or displacement at the output $[1,2]$. Unlike rigid-body mechanisms, compliant mechanisms gain some of their mobility from the deflection of flexible members rather than from movable joints only [3, 4].

\section{Advantages of Compliant Mechanisms}

Compliant mechanisms may be considered for use in a particular application for a variety of reasons. The advantages of compliant mechanisms are considered in two categories: cost reduction (part-count reduction, reduced assembly time and simplified manufacturing processes) and increased performance (increased precision, increased reliability, reduced wear, reduced weight, and reduced maintenance) [5]. Compliant mechanisms rely on the deflection of flexible members. Energy is stored in the form of strain energy in the flexible members. The stored energy is similar to the strain energy in a deflected spring and the effects of springs may be integrated into a compliant mechanisms design. In this manner, energy can easily be stored or transformed to be released at a later 
time [6]. Another advantage of compliant mechanisms is the ease with which they are miniaturized. Simple microstructures, actuators and sensors are seeing wide usage, and many other electro mechanical systems [7]. The reduction in the total number of parts and joints offered by compliant mechanisms is a significant advantage for the fabrication of micromechanics [8]. Another example of a compliant mechanism designed for harsh environments is the compliant gripping device holds a die. The die must be transported between several different chemicals without becoming damaged.

\section{Challenges of Compliant Mechanisms}

Compliant mechanisms present several challenges and disadvantages in some applications. The largest challenge is the relative difficulty in analyzing and designing compliant mechanisms [9]. Knowledge of mechanism analysis and synthesis methods and the deflection of flexible members are required. The combination of the two bodies of knowledge in compliant mechanisms requires not only an understanding of both, but also an understanding of their interactions in a complex situations [10].

\section{NEW AGE INDUSTRY DEVICE APPLICATIONS}

\section{- Automotive:}

Car wiper, steering part, gears, brakes, over running clutches, centrifugal clutches, orthoplaner flat spring, tyres etc

\section{- Aerospace:}

Adaptive compliant wing, compliant adaptive rotor blades, Proportional valve, etc

\section{- $\quad$ Medical Field :}

Compliant gripper used for medical field, Compliant heart valve, Medical invasive surgery, Surgical tools, Precision monitoring equipment etc.,

\section{- Highway safety and Flight safety:}

Antilock breaking system, Air bag deployment etc, Seat belt, helmets, etc

\section{- Others}

High precision equipment parts, Compliant die grippers,

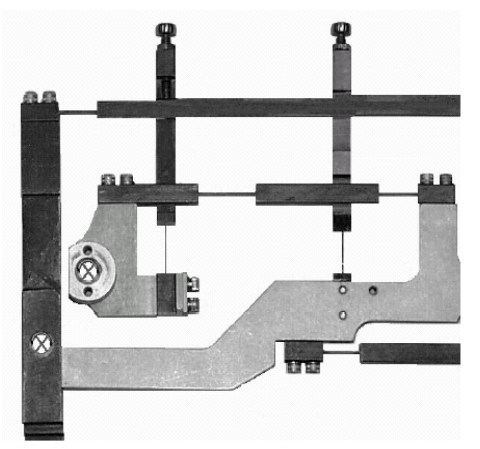

Figure 1: Compliant Precision Instrument 


\section{Topology Optimization}

Topology Optimizations is at the highest level in structural optimization. It is a material distribution method. The method used to find the best use of material for a body/domain. Also to find the optimum shape and size of a linearly elastic structure $[11,12]$. Topology Optimization procedures bring a multitude of possible design into the hands of the designer. The designer does not have to commit to any particular topology rather the optimization algorithm determines the optimal topology for the problem [13, 14]. There are two approaches of topological optimization schemes (Ground structure parameterization and Continuous material density parameterization). Practical implementation of these topology optimization schemes is better than shape optimization.

\section{DISPLACEMENT AMPLIFICATION OF A STRAIN ACTUATOR}

One type of smart material actuator typically used in adaptive structures, is an induced-strain piezo-ceramic stack actuator. Piezoceramic (PZT) actuators are solid-state devices, which offer the advantages of high energy density and high output force when compared with conventional methods of actuation [13,15]. One limitation of PZT actuators, however, is that they are capable of producing only 0.1 percent strain, resulting in a restricted range of motion. Thus, limiting the stroke Performance. To Increase the stroke length or displacement of the actuators, compliant amplifier have been designed from three types of configurations (Rectangular, taper, hexogonal domain) with surface constraints. The designed compliant amplifier integrated with strain actuators for the amplification of the actuator's displacement.

\section{DESIGN OF COMPLIANT AMPLIFIER}

The Design of Compliant Amplifier originated from basic design geometry or domain as shown in Figure 2.

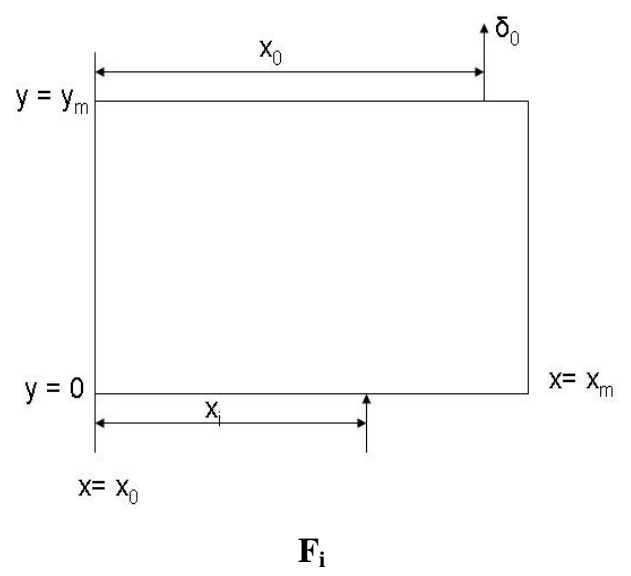

Figure 2: Basic Design Domain for Compliant Amplifier

Three types of configurations (Rectangular, Taper, Hexogonal domain) have been taken for analysis. Three types of configurations (Rectangular, taper, hexogonal domain) with surface constraints (left and right end of the surface is fixed) has been taken for analysis is shown in figure 3. 


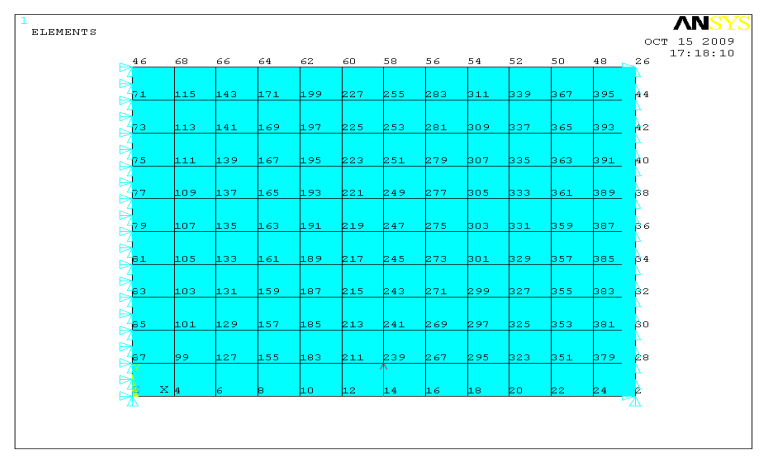

(a) Rectangular Domain with Surface Constraints

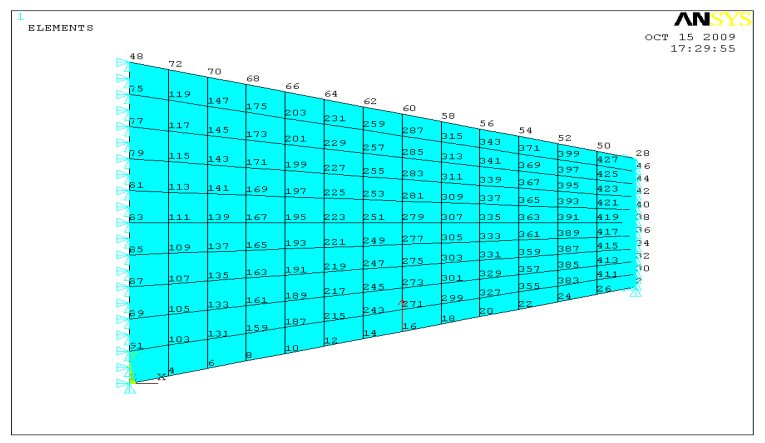

(b) Taper Domain with Surface Constraints

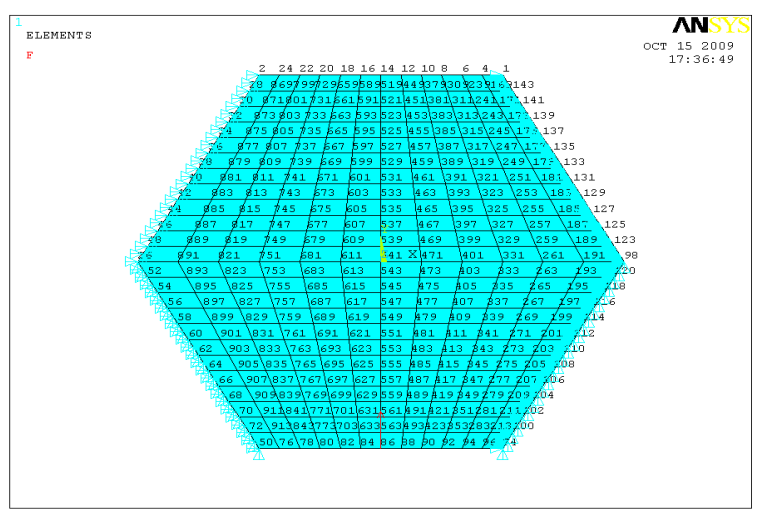

(c) Hexogonal Domain with Surface Constraints

Figure 3: Geometry Taken for Analysis with Surface Constraints

Analysis of geometry with surface constraints has been performed after the Topology Optimisation of Rectangular, Hexagonal and Taper domain with surface constraints

\section{ANALYSIS OF GEOMETRY WITH SURFACE CONSTRAINTS}

To study the effect of input location, the input force $\left(\mathrm{F}_{\mathrm{i}}\right)=300 \mathrm{~N}$, Output location $\left(\mathrm{X}_{0}=\mathrm{X}_{0} / \mathrm{X}_{\mathrm{m}}=0.5\right)$ are kept constant. Input force is applied at various input locations $\left(\mathrm{X}_{\mathrm{i}}=\mathrm{X}_{\mathrm{i}} / \mathrm{X}_{\mathrm{m}}\right)$ and the results are shown in Figure 4. 


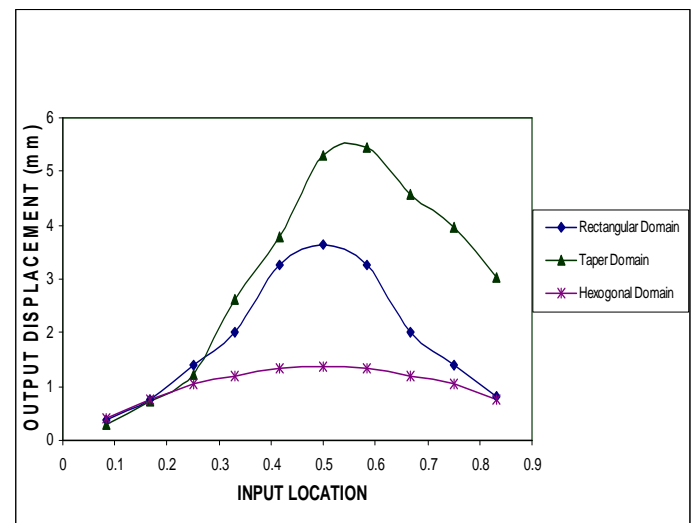

Figure 4: Effect of Input Location

\section{Effect of Input Location $\left(\mathbf{X}_{\mathbf{i}}\right)$}

To study the effect of input location, the input force $\left(\mathrm{F}_{\mathrm{i}}\right)=300 \mathrm{~N}$, Output location $\left(\mathrm{X}_{0}=\mathrm{X}_{0} / \mathrm{X}_{\mathrm{m}}=0.5\right)$ are kept constant. Input force is applied at various input locations $\left(\mathrm{X}_{\mathrm{i}}=\mathrm{X}_{\mathrm{i}} / \mathrm{X}_{\mathrm{m}}\right)$ and the results are shown in Figure 5

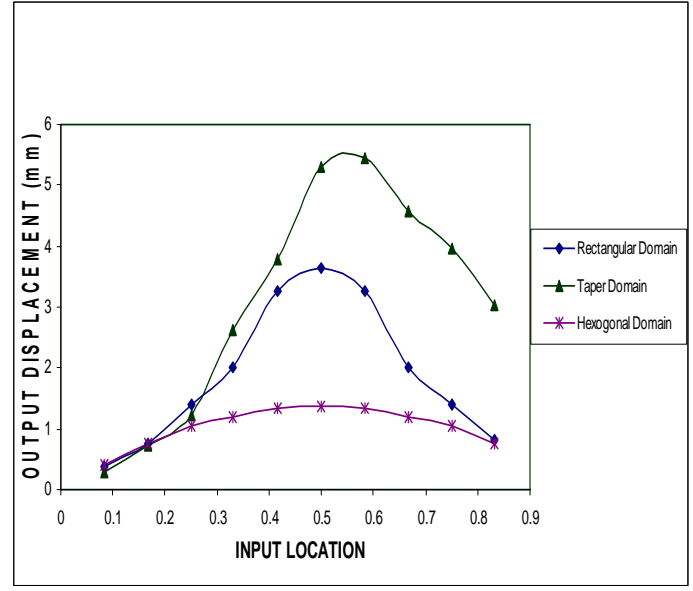

Figure 5: Effect of $\left(X_{i}\right)$ on Output Displacement

The Figure 5 shows the maximum output displacement is obtained at $\left(\mathrm{x}_{0} / \mathrm{x}_{\mathrm{m}}=0.5 \mathrm{~mm}\right)$ is $5.45 \mathrm{~mm}$.

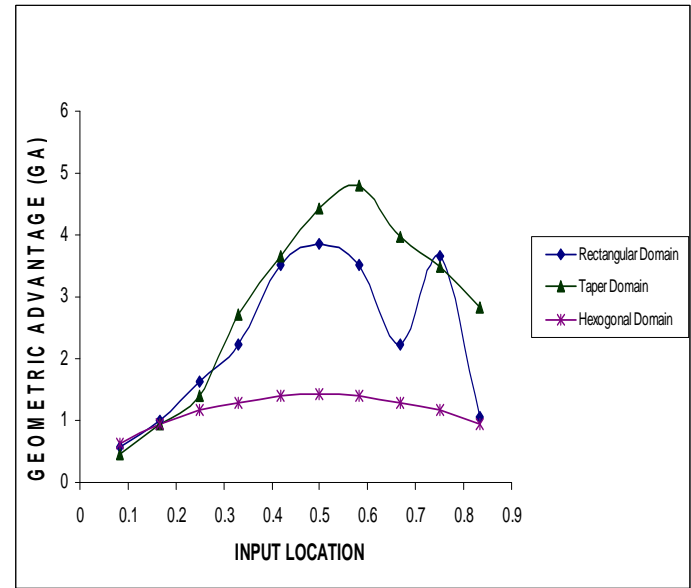

Figure 6: Effect of $\left(\mathrm{X}_{\mathrm{i}}\right)$ for Geometrical Advantage 
From the Figure 6 the Geometric advantage will be maximum at the input location $\mathrm{X}_{\mathrm{i}}=\left(\mathrm{x}_{\mathrm{i}}\right) /\left(\mathrm{x}_{\mathrm{m}}\right)=0.55$ and the corresponding value is 4.80. The output displacement increases and reaches maximum, at the midspan of the domain for rectangular, taper and hexagonal design domains. Compare with rectangular and hexagonal design domains, the taper domain give maximum output displacement for any input location.

\section{Effect of Output Locations}

To study the effect of output locations, the input force $\left(\mathrm{F}_{\mathrm{i}}\right)$, the input location $\left(\mathrm{X}_{\mathrm{i}}=\mathrm{X}_{\mathrm{i}} / \mathrm{X}_{\mathrm{m}}\right)$ are kept constant. The output locations $\left(\mathrm{X}_{0}=\mathrm{X}_{0} / \mathrm{X}_{\mathrm{m}}\right)$ is varied as $0.083,0.167,0.25,0.33,0.417,0.5,0.583,0.667,0.75$ and 0.833 and the results are shown in the Figure 7.

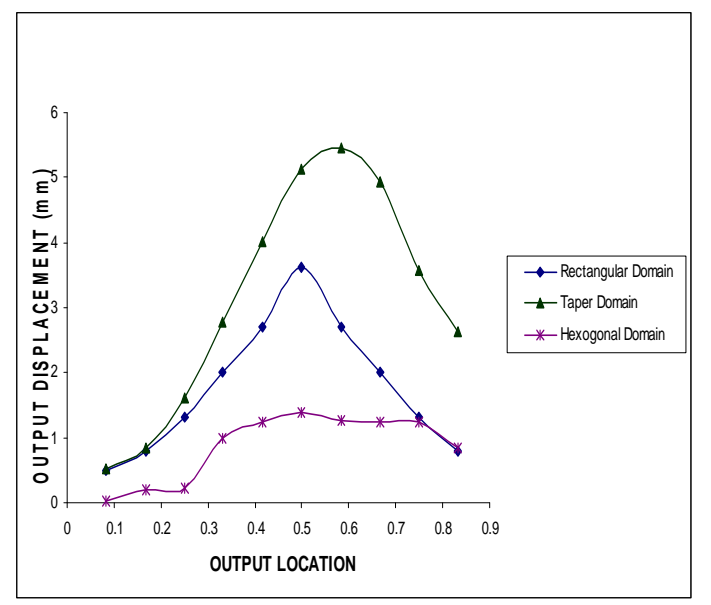

Figure 7: Effect of Output Locations $\left(\mathbf{X}_{\mathbf{0}}\right)$

The Figure 7 shows the output displacement maximum at the output location $\left(\mathrm{X}_{\mathrm{o}}=\mathrm{x}_{\mathrm{o}} / \mathrm{x}_{\mathrm{m}}=0.5\right)$ and the corresponding value is $5.45 \mathrm{~mm}$.

\section{Effect of Input Force $\left(\mathbf{F}_{\mathbf{i}}\right)$}

To study the effect of input force, the input location $\left(\mathrm{X}_{\mathrm{i}}=\mathrm{X}_{\mathrm{i}} / \mathrm{X}_{\mathrm{m}}\right)$, the output locations $\left(\mathrm{X}_{0}=\mathrm{X}_{0} / \mathrm{X}_{\mathrm{m})}\right.$ are kept constant. The magnitude of input force $\left(\mathrm{F}_{\mathrm{i}}\right) 100 \mathrm{~N}, 150 \mathrm{~N}, 200 \mathrm{~N}, 250 \mathrm{~N}, 300 \mathrm{~N}$ and $350 \mathrm{~N}$ applied at $\left(\mathrm{X}_{\mathrm{i}}=\mathrm{x}_{\mathrm{i}} / \mathrm{x}_{\mathrm{m}}=0.5\right)$. The output displacement values obtained are shown in Figure 8.

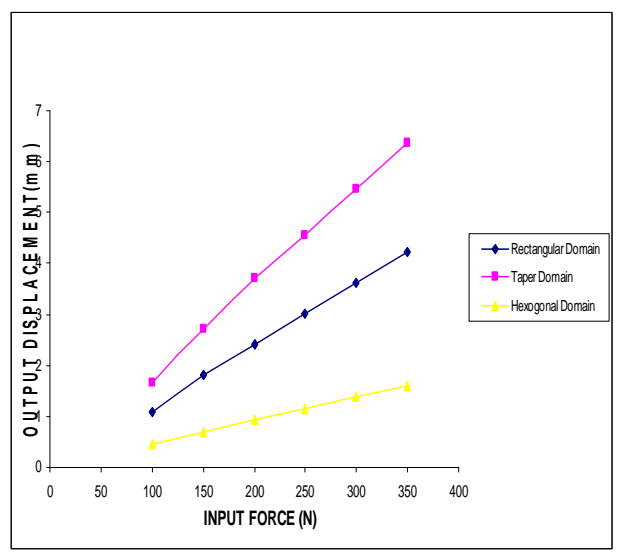

Figure 8: Effect of Input Force $\left(F_{i}\right)$ 
The Figure 8 shows, while increasing the magnitude of forces applied at the input location the output displacement also increased linearly.

\section{Effect of Aspect Ratio (A)}

To study the effect of aspect ratio, the aspect ratio of the domain has been varied from 1.2, 1.5, 2, 2.4 \& 3.0. Figure 9 shows, when the aspect ratio increases, the output displacement are found to increase because the size of the domain decreases the output displacement will naturally get increased.

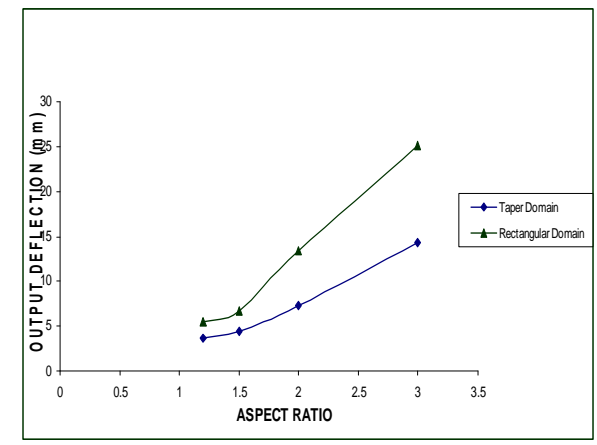

Figure 9: Effect of Aspect Ratio

The Figure 9 shows, the maximum output displacement is obtained, when the aspect ratio value is considered as 3.

\section{Effect of Thickness (T)}

To study the effect of thickness, the input force $\left(\mathrm{F}_{\mathrm{i}}\right)$, the input location $\left(\mathrm{X}_{\mathrm{i}}=\mathrm{X}_{\mathrm{i}} / \mathrm{X}_{\mathrm{m}}\right)$ and the output locations $\left(\mathrm{X}_{0}=\right.$ $\mathrm{X}_{0} / \mathrm{X}_{\mathrm{m}}$ ) are kept constant. The thickness of the domain is varied as $0.25 \mathrm{~mm}, 0.75 \mathrm{~mm}, 1 \mathrm{~mm}, 1.25 \mathrm{~mm}$ and the results of output displacement are shown in the Figure 10.

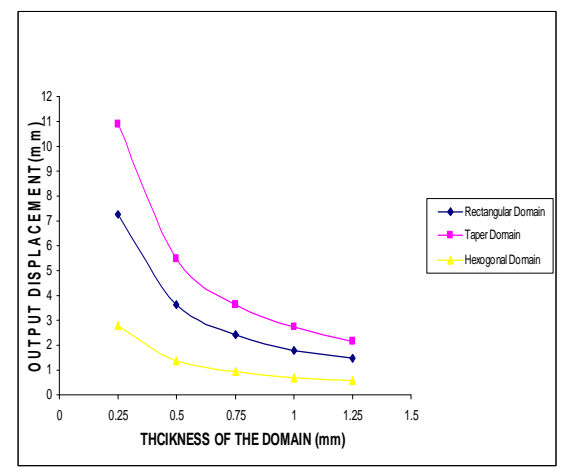

Figure 10: Effect of Thickness

Increase in domain thickness increases the cross sectional area of the element over which the input force is applied. The reduced stress results in lower input deflection in thickness of compliant mechanism reduce the output deflection for the given applied force.

\section{RESULTS AND DISCUSSIONS}

- The analysis conducted for Rectangular, Taper and Hexagonal design domain with boundary conditions (Both ends of the design domain fixed).

- The output displacement obtained at the output point of the Rectangular Domain, Taper sections and Hexogonal 
domain with surface constraints are compared and found that, the taper domain with point constraints gives the maximum.

\section{CONCLUSIONS}

- In this work three regular shapes of the design domains has been considered, however this method is applicable for any shape and size of the design domain. In the example problem the linear analysis has been considered, due to the requirement of topology optimization and minimum displacement amplification at the output point.

- The amplified displacement can be used for applications like opening and closing of proportional valves and vibrating a small chute etc.

\begin{tabular}{|c|c|l|}
\hline \multicolumn{3}{|c|}{ Symbols } \\
\hline $\mathrm{V}$ & - & Applied voltage \\
\hline $\mathrm{U}$ & - & Deflection vector at a \\
\hline $\mathrm{V}$ & - & Deflection vector at b \\
\hline $\mathrm{fd}$ & - & Dummy unit force $(\mathrm{N})$ \\
\hline $\mathrm{K}$ & - & Global stiffness matrix \\
\hline$\Delta_{\mathrm{in}}$ & - & Input deflection $(\mathrm{m})$ \\
\hline $\mathrm{f}_{\mathrm{a}}$ & - & Input force $(\mathrm{N})$ \\
\hline $\mathrm{a}$ & - & Input point \\
\hline$\Delta_{\text {out }}$ & - & Output deflection $(\mathrm{m})$ \\
\hline $\mathrm{b}$ & - & Output point \\
\hline $\mathrm{A}$ & - & Vector of design variable \\
\hline
\end{tabular}

\section{ACKNOWLEDGEMENTS}

The author acknowledges Sathyabama University for providing the facilities for the Numerical Experiments.

\section{REFERENCES}

1. Howell L. L, “Design of Complaint Mechanisms” Willey Publications, pp 5-25, (2002).

2. Ananthasuresh G. K. and Anupam Saxena 'A Computational Approach to the Number of Synthesis of Linkages', Journal of Mechanical Design, Transactions of ASME, Vol. 125, pp. 110-118, (2003).

3. Anandhasuresh G. K. and Saxena A., 'On an Optimal Property of Compliant Topologies', Journal of Structural Multidisc Optimization, Vol. 19, pp. 36-49, (2000).

4. K. Dhilleswaramma, K. B. Madhu Sahu \& CH. Krishna Rao, Improved Power Quality Features Using Fuzzy Based UPQC Topology for BLDC Drive Applications, International Journal of Electrical and Electronics Engineering Research(IJEER), Volume 5, Issue 1, January - February 2013, pp. 45-58

5. Howell LL and Midha A, "The Effects of a Compliant workforce on the input/output Characteristics of rigid link toggle mechanisms”, Journal of Mechanism and Machine Theory, Vol.30, No.6, pp.801-810, (1995).

6. Arun Kumar, G, and Srinivasan, PSS, "Topology Optimisation of Complaint Mechanism for Displacement Amplification in Strain Actuators,” IE (I)- Journal of Mechanical Engineering, Kolkatta, India, Vol. 86, pp.187-190, (2005).

7. Arun Kumar, and Srinivasan, PSS, "Design of Displacement Amplifying Complaint Mechanism with integrated Strain Actuator using Topology Optimisation," International Journal of Mechanical Engineering Science, SAGE Publishers, Vol.220, Issue 10, pp.1219-1228, (2006). 
8. Canfield S. and Fracker M., 'Topology Optimization of Compliant Mechanical Amplifiers', Journal of Structural Multidisc Optimization, Vol. 20, pp. 269-279, (2000).

9. Fracker M and Kota S, "Topological Synthesis of Compliant Mechanisms Using Multi-criteria Optimisation”, Journal of Mechanical Design, Transaction of ASME, Vol.119, pp-238-245, 1997.

10. Arunkumar, G. Santhakumar, "Design of compliant mechanisms by topology optimization for strain actuators and engineering support “, International Review of Mechanical Engineering”, Vol.6, pp.979-989, 2012.

11. Howell, LL and Midha, A, "A method for the Design of Compliant Mechanisms with Small-Length Flexural Pivots," ASME Journal of Mechanical Design, Vol.116, pp.280-290, 2012.

12. Kota, S and Hetrick, J, "Synthesizing high-performance compliant stroke amplification systems for MEMS," Proceedings of the IEEE Micro Electro Mechanical systems, pp.164-169, (2000).

13. Dong $X u$ and Anandthasuresh $G K$, "Freeform skeletal shape Optimization of Compliant Mechanisms", Journal of Mechanical Design, Vol.125, pp-253-261.

14. Kota S and Rodgers SM, "Design of Compliant Mechanisms: Application to MEMS", Journal of Analog Integrated Circuits and Signal Processing, Vol.29, pp7-15, (2001)

15. Lau G. K and Du H and Lim M. K), "Use of Functional specifications as Objective functions in Topological Optimisation of compliant mechanisms”, Journal of Computer Methods in Applied Mechanics and Engineering, Vol.190, PP.4421-4433, 2001.

16. Sigmond $O$ and Torquato, "Design of Smart Composites Materials Using Topology Optimisation", Smart Materials and Structures, Vol.8, pp.365-379, (1999). 
